\title{
Association between belief and attitude toward preference of complementary alternative medicine use
}

This article was published in the following Dove Press journal:

Patient Preference and Adherence

10 May 2017

Number of times this article has been viewed

\author{
Farida Islahudin' \\ Intan Azura Shahdan² \\ Suzani Mohamad-Samuri ${ }^{3}$ \\ 'Faculty of Pharmacy, Universiti \\ Kebangsaan Malaysia, Kuala Lumpur, \\ ${ }^{2}$ Kulliyah of Science, International \\ Islamic University Malaysia-Kuantan \\ Campus, Kuantan, Pahang, ${ }^{3}$ Faculty \\ of Arts, Computing and Creative \\ Industry, Universiti Pendidikan Sultan \\ Idris, Tanjong Malim, Perak Darul \\ Ridzuan, Malaysia
}

Background: There is a steep increase in the consumer use of complementary alternative medicine (CAM), with many users unaware of the need to inform their health care providers. Various predictors including psychosocial factors such as beliefs and behavior have been accounted for preference toward CAM use, with varying results.

Methods: This study investigates the belief and attitude regarding preference toward CAM use among the Malaysian population by using a questionnaire-based, cross-sectional study.

Results: A large majority of the 1,009 respondents admitted to taking at least one type of CAM ( $\mathrm{n}=730,72.3 \%)$. Only $20(1.9 \%)$ respondents were found to have negative beliefs (total score <35), $4(0.4 \%)$ respondents had neutral beliefs (total score $=35)$, and $985(97.6 \%)$ respondents had positive belief toward CAM (total score >36). A total of 507 (50.2\%) respondents were categorized as having a negative CAM attitude, while 502 (49.8\%) respondents were categorized as having a positive CAM attitude. It was demonstrated that there was a positive correlation between belief and attitude score $(\rho=0.409, P<0.001)$. Therefore, the higher the belief in CAM, the more positive the attitude was toward CAM. Those who were using CAM showed a stronger belief $(P=0.002)$, with a more positive attitude $(P<0.001)$ toward it, than those who were not using CAM.

Conclusion: Identifying belief regarding preference toward CAM use among the public could potentially reveal those with a higher tendency to use CAM. This is important as not everyone feels the need to reveal the use of CAM to their health care providers, which could lead to serious repercussions such as interactions and adverse effects.

Keywords: attitude, belief, complementary and alternative medicine, Malaysia

\section{Introduction}

The use of complementary alternative medicine (CAM) has become increasingly popular. ${ }^{1}$ In Malaysia, traditional alternative medicine and CAM are defined as healthrelated practices that are not provided by registered conventional medical practitioners to prevent, treat, and/or manage illness and/or preserve the mental and physical wellbeing of individuals. ${ }^{2}$ A community-wide study on the use of CAM in Malaysia revealed that $\sim 90 \%$ of patients admitted to taking CAM for health. ${ }^{3}$ The main reasons for CAM use were for health maintenance, disease prevention, and treatment.

Various sociodemographic factors are associated with CAM use. Among them, gender, education, and household income were factors that were found to affect preference toward CAM. ${ }^{4,5}$ In rural communities, those with a lower income and a higher education level were more likely to prefer CAM use. On the other hand, among patients with chronic illness, younger patients with a higher education were found to be
Correspondence: Farida Islahudin Faculty of Pharmacy, Universiti Kebangsaan Malaysia, Jalan Raja Muda Abdul Aziz, 50300 Kuala Lumpur, Malaysia

Tel +60 392897689

Email faridaislahudin@yahoo.com 
more likely to use CAM. ${ }^{6}$ The variation in findings attributed to education could be due to the differences in populations.

Apart from demographic factors, complex psychosocial factors may also affect the preference toward CAM. Perceptions and attitude patterns have been greatly researched in an attempt to understand preference toward CAM use, especially in chronic ill patients. ${ }^{6,7}$ To most consumers, CAM is believed to be a much safer alternative than conventional medicine. ${ }^{8}$ Furthermore, CAM is seen as a holistic approach to health and well-being over which to maintain personal control. ${ }^{9}$ As such, the satisfaction achieved from combining CAM with conventional medication reflects the need to not limit the use of conventional medicine. ${ }^{7}$ To that end, the ease of availability and perceived efficacy of natural approaches has been reported as the main predictor of preference toward CAM use in promoting health. ${ }^{10}$

Non-disclosure of CAM is common among the population. ${ }^{9}$ This feature is of utmost importance as health care professionals lack the realization that patients and the public wish for a more holistic approach to their health. This stems from the desire to retain control over decisions associated with their well-being. The understanding of the association between belief and attitude regarding preference toward CAM may lend a hand in identifying those that have a tendency to use CAM. Therefore, identifying the association between belief and attitude toward CAM in the local population was performed.

\section{Methods}

\section{Study design}

This was a prospective study performed among the public in Malaysia. Questionnaires were distributed to respondents by using convenient sampling. Malaysian respondents aged $\geq 18$ years were included in the study. Questionnaires that were not completed were excluded. Questionnaires were distributed, and written informed consent was obtained from all respondents who agreed to participate. All answers were treated confidentially. Ethical approval was obtained from the Universiti Kebangsaan Malaysia local medical ethics and research committee (JEP-2016-462).

The sample size of respondents was calculated based on a previous work. ${ }^{11}$ Based on $\sim 6.35$ million households in Malaysia, a sample size of 384 respondents was required. However, in order to improve the power of the study and to account for incomplete questionnaires, $\sim 1,000$ respondents were targeted.

\section{Questionnaire}

The questionnaire was divided into three sections. The first section consisted of demographic and health data.
Information such as age, gender, ethnicity, family members working in the medical field, long-term illness, medication, general health measurement, use of CAM, and the type of CAM used was collected.

The second section of the questionnaire consisted of the Complementary Alternative Medicine Health Belief Questionnaire (CHBQ). ${ }^{12}$ This section was based on 10 statements that assessed an individual's belief on the use of CAM. Each statement was followed by a 7-point Likert scale response ranging from 1 (absolutely disagree) to 7 (absolutely agree). The statements were scored so that a higher response indicated greater endorsement in CAM belief. ${ }^{12}$ Three CHBQ statements were worded negatively to minimize the tendency of respondents to reply in a consistent manner. The maximum possible score was 70 with a hypothetical midpoint of 35 denoting neutral belief. ${ }^{13}$ A minimum score of 10 was representative of the least favorable belief toward CAM. Scores between 36 and 69 were representative of a positive belief, while scores between 11 and 34 correlate negatively with belief toward CAM.

The third section consisted of 13 statements on attitude toward the use of CAM, as previously described. ${ }^{14}$ Statements 1-6 assessed positive beliefs about CAM. Items in this subscale referred to information, less side effects, natural products, access, empowerment, and self-healing. Statements 7-10 assessed environmental influences on the use of CAM based on the knowledge about CAM treatments and whether their parents or family used CAM. Psychological comfort represents reasoning behind their attitudes toward CAM and was assessed by statements 11-13. Respondents were asked to indicate their level of agreement, with each statement based on a 5-point Likert scale ranging from 1 (strongly disagree) to 5 (strongly agree). The scores were then summed up with a maximum score of 65 . The mean score of the study population was then used to define positive and negative attitudes toward CAM. Scores that were equal and below the mean were defined as negative attitude and low likelihood of CAM use. ${ }^{14}$ Scores above the mean were defined as positive attitude with a higher likelihood to use CAM. ${ }^{14}$

\section{Data analyses}

Data analyses were performed by using the statistical package SPSS version 22.0 (IBM, Armonk, NY, USA). Descriptive statistics, such as mean, standard deviation (SD), and frequency, were used to analyze continuous and categorical data, such as respondent's demographics and their knowledge level. An independent $t$-test or analysis of variance was used to compare the mean values between 
two or more groups, respectively. A chi-squared test was used to determine the association between categorical data. The association between belief and attitude was assessed by using a Pearson correlation. A significance level of $P<0.05$ was considered statistically significant.

\section{Results \\ Demographic data}

A total of 1,009 respondents were included during the study period. The mean age of the respondents was $28.3 \pm 11.04$ years. A large number of the respondents were of Malay ethnicity $(n=826,81.9 \%)$, followed by Chinese $(n=80,7.9)$, Indian $(n=34,3.4 \%)$, and others $(n=6.9,6.8 \%)$. Approximately half of the respondents were female (53\%, $n=536)$. A total of $42 \%(n=422)$ respondents had a family member working in the health care industry. Long-term illness was present in $16.3 \%(n=161)$ respondents, although a total of $35.9 \%(n=351)$ admitted to taking prescribed medications. The perception of health was poor in $4(0.4 \%)$ respondents, fair in 78 (7.7\%) respondents, good in 424 (42\%) respondents, very good in 341 (33.8\%) respondents, and excellent in $162(16.2 \%)$ respondents. A large majority of the respondents admitted to taking at least one type of CAM ( $n=730,72.3 \%)$ such as vitamins $(n=511,50.6 \%)$, herbs $(n=340,33.7 \%)$, massages $(n=127,12.6 \%)$, acupuncture $(n=28,2.8 \%)$, and aromatherapy $(n=67,6.6 \%)$. The reasons for CAM use were preventing illness ( $\mathrm{n}=253,25.1 \%)$, treating illness $(n=273,27.1 \%)$, and promoting health $(n=291,28.8 \%)$.

\section{CHBQ and CAM attitude scores}

The average CHBQ score for each statement in the study population was $>4.7 \pm 1.0$. Each statement ranged from a scale of 1 to 7 (score 1 [absolutely disagree] to 7 [absolutely agree]). The lower scores found for statements 6 ,
7 , and 8 were negatively worded. The mean total score of the study was $45.4 \pm 5.2$ out of a total of 70. A higher score indicates a higher endorsement in their belief for CAM. Out of 1,009 respondents, only 20 (1.9\%) were found to have negative belief toward CAM (total score $\leq 34$ ) while $4(0.4 \%)$ respondents had neutral belief toward CAM (total score $=35)$. The remaining majority $(n=985,97.6 \%)$ had positive belief toward CAM (total score $\geq 36$ ). Respondents in the study population were found to believe strongly toward integrating patient's expectations, health beliefs, and values in the patient care process and that the task of a health care provider is to assist in the process of healing (Table 1).

CAM attitude scores are shown in Table 2. The average CAM attitude score for each statement in the study population was $>3.5 \pm 0.9$. Each statement ranged from a score of 1 to 5 (1 [strongly disagree] to 5 [strongly agree]). The mean total score of the study was $47.9 \pm 7.6$ out of a total of 65 . Scores in the range of 0-48 were defined as a negative attitude and low likelihood to use CAM. Scores in the range 49-65 were defined as a positive attitude and a higher likelihood to use CAM. A total of 507 (50.2\%) respondents were categorized as negative attitude toward CAM, while 502 (49.8\%) respondents were categorized as positive attitude toward CAM. On average, respondents felt that they would more likely use CAM if they had more knowledge on it.

The association between demographic characteristic with CHBQ and CAM attitude score was sought (Table 3). It was demonstrated that female respondents were more likely to believe in CAM $(P<0.01)$ and had a more positive attitude toward CAM use $(P<0.001)$ more than their male counterparts. Respondents with a long-term illness was also more likely to believe in CAM $(P<0.001)$ and had a more positive attitude toward CAM $(P=0.024)$ than those who did not have a long-term illness. Interestingly, respondents with a poor perception of health tend to believe more

Table I CHBQ score of the study population $(\mathrm{N}=\mathrm{I}, 009)$

\begin{tabular}{|c|c|c|}
\hline No & CHBQ & Mean \pm SD \\
\hline I & The physical and mental health is maintained by an underlying energy or vital force & $4.9 \pm 1.1$ \\
\hline 2 & Health and disease are a reflection of balance between positive life-enhancing forces and negative destructive forces & $4.7 \pm 1.0$ \\
\hline 3 & The body is essentially self-healing, and the task of a health care provider is to assist in the healing process & $5.1 \pm 1.0$ \\
\hline 4 & A patient's symptoms should be regarded as a manifestation of a general imbalance or dysfunction affecting the whole body & $4.9 \pm 1.0$ \\
\hline 5 & A patient's expectations, health beliefs, and values should be integrated into the patient care process & $5.1 \pm 1.0$ \\
\hline 6* & Complementary therapies are a threat to public health & $3.9 \pm 1.5$ \\
\hline $7^{*}$ & Treatments not tested in a scientifically recognized manner should be discouraged & $3.3 \pm 1.3$ \\
\hline $8^{*}$ & Effects of complementary therapies are usually the result of a placebo effect & $3.5 \pm 1.0$ \\
\hline 9 & Complementary therapies include ideas and methods from which conventional medicine could benefit & $4.9 \pm 1.0$ \\
\hline 10 & Most complementary therapies stimulate the body's natural therapeutic powers & $4.8 \pm 1.1$ \\
\hline
\end{tabular}

Note: *Items that were negatively worded.

Abbreviations: $\mathrm{CHBQ}$, Complementary Alternative Medicine Health Belief Questionnaire; SD, standard deviation. 
Table 2 CAM attitude scores of the study population $(\mathrm{N}=\mathrm{I}, 009)$

\begin{tabular}{lll}
\hline No & Attitude toward CAM & Mean \pm SD \\
\hline I & CAM providers give good information on maintaining a healthy lifestyle & $3.7 \pm 0.9$ \\
2 & There are less side effects when taking natural remedies & $3.7 \pm 0.9$ \\
3 & CAM involves natural plant formulas, which are more healthy than taking drugs given by the medical doctor & $3.8 \pm 0.9$ \\
4 & I would be more likely to use CAM if there were more CAM clinics & $3.7 \pm 0.9$ \\
5 & I feel more empowered when using CAM because CAM providers involve me in decisions about their health care treatments & $3.5 \pm 0.9$ \\
6 & I believe that CAM builds up the body's own defenses and promotes self-healing & $3.8 \pm 0.8$ \\
7 & The more knowledge I have about CAM, the more likely I will use it & $3.9 \pm 0.8$ \\
8 & Parent(s) and family can influence CAM use by exposing me to it & $3.8 \pm 0.9$ \\
9 & I am more likely to use CAM if my friends are using it & $3.5 \pm 0.9$ \\
I0 & I am more likely to use CAM if coaches and teachers discuss it with me & $3.7 \pm 0.9$ \\
II & If I believe in the physical, mental, and spiritual aspects of health, I am more likely to use CAM & $3.7 \pm 0.9$ \\
I2 & Fear of the discomfort of treatments from medical doctors makes me more likely to use CAM & $3.5 \pm$ I.0 \\
I3 & I believe that taking CAM therapies is not harmful & $3.8 \pm 0.9$ \\
\hline
\end{tabular}

Abbreviations: CAM, complementary alternative; SD, standard deviation.

in CAM $(P<0.001)$, although their attitude toward it was much more negative $(P=0.005)$. Those who were actually using CAM had a stronger belief in CAM $(P=0.002)$ with a more positive attitude $(P<0.001)$ toward it than those who were not using CAM.

\section{Association between CHBQ and CAM attitude score}

The association between CHBQ and CAM attitude score was analyzed. It was demonstrated that there was a positive correlation between CHBQ and CAM attitude score $(\rho=0.409$,

Table 3 Association between demographics with CHBQ and CAM attitude scores $(N=I, 009)$

\begin{tabular}{|c|c|c|c|c|c|c|}
\hline \multirow[t]{2}{*}{ Characteristics } & \multicolumn{3}{|l|}{ CHBQ } & \multicolumn{3}{|c|}{ CAM attitude } \\
\hline & Scores & $P$-value & & Scores & $P$-value & \\
\hline Age, years & & $\rho=-0.123$ & $<0.001$ & & $\rho=-0.055$ & $>0.05$ \\
\hline Gender & & & $<0.01$ & & & $<0.001$ \\
\hline Male & $44.6 \pm 3.8$ & $t=5.317$ & & $48.8 \pm 6.9$ & $t=-4.758$ & \\
\hline Female & $47.5 \pm 5.7$ & $d f=504$ & & $52.3 \pm 5.9$ & $d f=504$ & \\
\hline Ethnic & & & $>0.05$ & & & $>0.05$ \\
\hline Malay & $47.6 \pm 5.2$ & $F=2.585$ & & $47.8 \pm 7.3$ & $F=|.87|$ & \\
\hline Chinese & $44.1 \pm 4.7$ & $d f=I, 005$ & & $48.6 \pm 9.2$ & $d f=1,005$ & \\
\hline Indian & $44.5 \pm 5.8$ & & & $46.7 \pm 7.4$ & & \\
\hline Others & $44.9 \pm 5.3$ & & & $46.1 \pm 9.3$ & & \\
\hline Family in health care & & & $>0.05$ & & & $>0.05$ \\
\hline Yes & $45.2 \pm 5.1$ & $t=-1.079$ & & $48.2 \pm 8.1$ & $t=1.419$ & \\
\hline No & $45.5 \pm 5.3$ & $d f=1,003$ & & $47.6 \pm 7.3$ & $d f=1,003$ & \\
\hline Long-term illness & & & $<0.001$ & & & 0.024 \\
\hline Yes & $44.1 \pm 5.3$ & $t=-3.507$ & & $46.6 \pm 8.9$ & $t=-2.254$ & \\
\hline No & $45.7 \pm 5.2$ & $d f=984$ & & $48.1 \pm 7.4$ & $d f=984$ & \\
\hline Prescription medication & & & 0.008 & & & $>0.05$ \\
\hline Yes & $44.8 \pm 5.4$ & $t=-2.676$ & & $47.9 \pm 7.9$ & $t=0.728$ & \\
\hline No & $45.8 \pm 5.2$ & $d f=976$ & & $47.6 \pm 7.4$ & $d f=976$ & \\
\hline Perception of general health & & & $<0.001$ & & & 0.005 \\
\hline Poor & $52.8 \pm 1.3$ & $F=7.8$ & & $36.8 \pm 6.4$ & $F=3.739$ & \\
\hline Fair & $43.7 \pm 3.9$ & $d f=I, 004$ & & $46.1 \pm 5.0$ & $d f=1,004$ & \\
\hline Good & $45.1 \pm 4.2$ & & & $48.3 \pm 6.9$ & & \\
\hline Very good & $46.3 \pm 6.1$ & & & $47.9 \pm 8.3$ & & \\
\hline Excellent & $44.8 \pm 5.6$ & & & $47.6 \pm 8.6$ & & \\
\hline Use of CAM & & & 0.002 & & & $<0.001$ \\
\hline Yes & $45.7 \pm 5.2$ & $t=3.091$ & & $48.8 \pm 7.3$ & $t=6.876$ & \\
\hline No & $44.6 \pm 5.2$ & $d f=I, 007$ & & $45.3 \pm 7.3$ & $d f=1,007$ & \\
\hline
\end{tabular}

Abbreviations: CHBQ, Complementary Alternative Medicine Health Belief Questionnaire; CAM, complementary alternative medicine; df, degrees of freedom. 


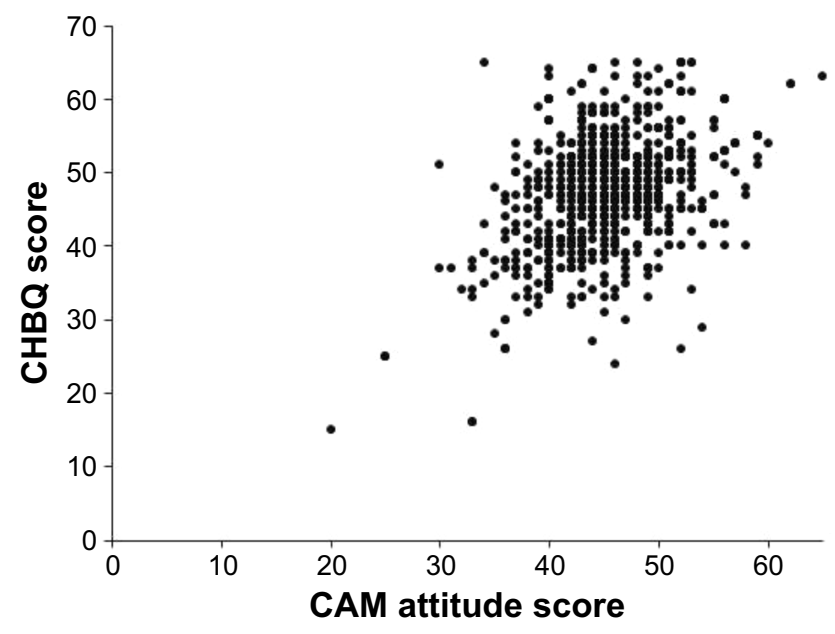

Figure I Correlation between $\mathrm{CHBQ}$ and CAM attitude score in the study population $(\mathrm{N}=\mathrm{I}, 009)$.

Abbreviations: $\mathrm{CHBQ}$, Complementary Alternative Medicine Health Belief Questionnaire; CAM, complementary alternative medicine.

$P<0.001$ ) (Figure 1). Therefore, the stronger the belief in CAM, the more positive the attitude toward CAM.

\section{Discussion}

Due to the failure of modern revolutionary medicine to cure debilitating chronic diseases, such as cancer, diabetes, and hypertension, CAM has become increasingly popular due to its holistic philosophical approach. ${ }^{15}$ In view of the recent upsurge of interest in CAM that focuses on natural forces of mind, body, and soul, a number of studies have been performed to understand the association behind the preference toward CAM use in the Malaysian population. The high demand of CAM in Malaysia has prompted an establishment of 10 integrated CAM hospitals under the Ministry of Health Malaysia. ${ }^{16}$ However, only patients under the management of conventional treatment are referred to these establishments. The use of CAM is known to be popular in patients regardless of health status. In most of the developing countries, $\sim 70 \%$ of the population were admitted to taking CAM, with the bulk originating from Asia. ${ }^{17}$ In Malaysia, it has been reported that CAM use is popular among the public, with prevalence of CAM use of $\sim 60 \%,{ }^{16}$ similar to the current work.

The use of CAM has been highly associated with positive belief toward CAM use. ${ }^{4,18}$ This is especially true in patients with chronic illness. The current work demonstrated that the majority of the public had positive beliefs toward CAM use. The tendency to believe in integrating health beliefs, and that the role of the health provider is to assist in the healing process, was found to be the most positively believed statement. This was found to be similar to other work among Malaysians. ${ }^{5}$ The need to integrate prayers among cancer patients was found to help in producing relief. ${ }^{19}$ Use of supplements on the other hand was also believed to improve health and was similarly popular as a more natural substitute or adjunct to conventional medicine in both Asian and Western populations. ${ }^{19,20}$ Similarly true in other work among Malaysians, female respondent's belief preferred CAM use more than their male counterparts. ${ }^{5}$ The reason for a higher prevalence of CAM use in female has been suggested to be due to the neglect of women's health care needs in public health care. ${ }^{5}$ Unmet goals with individual health care needs were also the main reasons among female respondents in Norway. ${ }^{21}$ Furthermore, the higher utilization of health care ${ }^{22}$ was another possible reason why female respondents felt the need to seek alternative management to conventional care.

Attitude toward CAM has also been associated with CAM use. ${ }^{4}$ In women, CAM use was considered a more holistic approach to health and well-being over which they were able to maintain their personal control. ${ }^{9}$ A positive attitude toward CAM suggests a dynamic equilibrium between holistic health beliefs and personal behavior for seeking CAM treatments. ${ }^{23}$ Respondents in Kuwait were found to have a positive attitude toward CAM, although a majority were found to disagree that CAM was much better and safer than conventional medicine. ${ }^{24}$ Interestingly, the current work among the Malaysia public attitude varied, with most of the respondents agreeing to CAM due to the lack of side effects compared to conventional medicine and natural approach to health. This misleading attitude should be supported with appropriate CAM education to ensure that the positive attitude toward CAM is sustained with evidence-based medicine.

The association between belief and attitude was observed in the current work. A number of respondents admitted to taking CAM among those with a positive attitude and belief. It is known that the use of CAM is highly popular in Malaysia, ${ }^{19}$ with the majority of the public admitting to taking at least one type of CAM. ${ }^{3,19}$ However, taking CAM can result in potential interactions with conventional medicine. ${ }^{25}$ Without appropriate guidance, CAM can also potentially interact with vital organs if left unmonitored. ${ }^{26}$ Health care professionals are in the best position to ensure patients make informed decision regarding CAM use in order to minimize adverse reactions and interactions.

The aim of the current work to identify the association between belief and attitude was successfully achieved. However, it should be noted that with all questionnaire-based surveys, the validity of the data may be limited by the honesty of respondents in answering the questionnaire. With this in mind, identifying the belief toward CAM among the public could potentially reveal those who have a higher tendency for preference to use CAM. This is especially important as 
not everyone feels the need to reveal the use of CAM to their health care providers. This could lead to serious repercussions, and hence a deeper understanding of the belief and attitude toward CAM could help identify those who are possible users of complementary and alternative management.

\section{Acknowledgment}

The authors would like to express their gratitude to all respondents who participated in the study.

\section{Author contributions}

All authors contributed toward data analysis, drafting and critically revising the paper and agree to be accountable for all aspects of the work.

\section{Disclosure}

The authors report no conflicts of interest in this work.

\section{References}

1. World Health Organization. National Policy on Traditional Medicine and Regulation of Herbal Medicines: Report of a WHO Global Survey. Geneva; May 2005. Available from: http://apps.who.int/medicinedocs/ en/d/Js7916e/. Accessed May 2, 2017.

2. Traditional \& Complementary Medicine Division [webpage on the Internet]. National Policy of Traditional \& Complementary Medicine. Ministry of Health Malaysia; 2007. Available from: http://tcm.moh.gov. my/v4/modules/mastop_publish/?tac=48. Accessed December 5, 2016.

3. Siti ZM, Tahir A, Farah AI, et al. Use of traditional and complementary medicine in Malaysia: a baseline study. Complement Ther Med. 2009; 17(5):292-299.

4. Ganasegeran K, Rajendran AK, Al-Dubai SA. Psycho-socioeconomic factors affecting complementary and alternative medicine use among selected rural communities in Malaysia: a cross-sectional study. PloS One. 2014;9(11):e112124.

5. Jaiswal K, Bajait C, Pimpalkhute S, Sontakke S, Dakhale G, Tathod Y. Perception of complementary and alternative medicine amongst medical students: a questionnaire based study. World J Pharm Sci. 2015;3(9): 1899-1904

6. Weizman AV, Ahn E, Thanabalan R, et al. Characterisation of complementary and alternative medicine use and its impact on medication adherence in inflammatory bowel disease. Aliment Pharmacol Ther. 2012; 35(3):342-349.

7. Arthur K, Belliard JC, Hardin SB, Knecht K, Chen CS, Montgomery S. Practices, attitudes, and beliefs associated with complementary and alternative medicine (CAM) use among cancer patients. Integr Cancer Ther. 2012;11(3):232-242.

8. Mitha S, Nagarajan V, Babar MG, Siddiqui MJ, Jamshed SQ. Reasons of using complementary and alternative medicines (CAM) among elderly Malaysians of Kuala Lumpur and Selangor states: an exploratory study. $J$ Young Pharm. 2013;5(2):50-53.
9. Warriner S, Bryan K, Brown AM. Women's attitude towards the use of complementary and alternative medicines (CAM) in pregnancy. Midwifery. 2014;30(1):138-143.

10. Sivadasan S, Ali AN, Lin LW, Balakrishnan D, Ramachandran S, Dhanaraj SA. Use of complementary and alternative medicine in the population of Kedah Darul Aman, Malaysia. Int J Pharm Sci Res. 2014; 5(4):1263-1273.

11. Barlett JE, Kotrlik JW, Higgins CC. Organizational research: determining appropriate sample size in survey research. Inf Technol Learn Performance J. 2001;19(1):43-50.

12. Lie D, Boker J. Development and validation of the CAM Health Belief Questionnaire (CHBQ) and CAM use and attitudes amongst medical students. BMC Med Educ. 2004;4(2):1.

13. Riccard CP, Skelton M. Comparative analysis of 1st, 2 nd, and 4th year MD students' attitudes toward complementary alternative medicine (CAM). BMC Res Notes. 2008;1:84.

14. Patterson C, Arthur H. A complementary alternative medicine questionnaire for young adults. Integr Med Insights. 2009;4:1.

15. Kuunibe N, Domanban PB. Demand for complementary and alternative medicine in Ghana. Int J Humanit Soc Sci. 2012;2:288-294.

16. Abuduli M, Ezat WP, Aljunid S. Role of traditional and complementary medicine in universal coverage. Malaysian J Public Health Med. 2011;11(2):1-5.

17. Limsatchapanich S, Sillabutra J, Ounprasertpong Nicharojana L. Factors related to the use of complementary and alternative medicine among people living with HIV/AIDS in Bangkok, Thailand. Health Sci J. 2013;7(4):436-446.

18. Bauml JM, Chokshi S, Schapira MM, et al. Do attitudes and beliefs regarding complementary and alternative medicine impact its use among patients with cancer? A cross-sectional survey. Cancer. 2015; 121(14):2431-2438.

19. Chui PL, Abdullah KL, Wong LP, Taib NA. Prayer-for-health and complementary alternative medicine use among Malaysian breast cancer patients during chemotherapy. BMC Complement Altern Med. 2014;14(1):1.

20. Velicer CM, Ulrich CM. Vitamin and mineral supplement use among US adults after cancer diagnosis: a systematic review. J Clin Oncol. 2008;26(4):665-673.

21. Kristoffersen AE, Stub T, Salamonsen A, Musial F, Hamberg K. Gender differences in prevalence and associations for use of CAM in a large population study. BMC Complement Altern Med. 2014;14(1):463.

22. Hamberg K. Gender bias in medicine. Womens Health (Lond). 2008; 4(3):237-243

23. McFadden KL, Hernández TD, Ito TA. Attitudes toward complementary and alternative medicine influence its use. Explore. 2010;6(6): 380-388.

24. Awad A, Al-Shaye D. Public awareness, patterns of use and attitudes toward natural health products in Kuwait: a cross-sectional survey. BMC Complement Altern Med. 2014;14(1):105.

25. Bello N, Winit-Watjana W, Baqir W, McGarry K. Disclosure and adverse effects of complementary and alternative medicine used by hospitalized patients in the North East of England. Pharm Pract. 2012; 10(3): 125-135.

26. Niggemann B, Grüber C. Side-effects of complementary and alternative medicine. Allergy. 2003;58(8):707-716.
Patient Preference and Adherence

\section{Publish your work in this journal}

Patient Preference and Adherence is an international, peer-reviewed, open access journal that focuses on the growing importance of patient preference and adherence throughout the therapeutic continuum. Patient satisfaction, acceptability, quality of life, compliance, persistence and their role in developing new therapeutic modalities and compounds to optimize

\section{Dovepress}

clinical outcomes for existing disease states are major areas of interest for the journal. This journal has been accepted for indexing on PubMed Central. The manuscript management system is completely online and includes a very quick and fair peer-review system, which is all easy to use. Visit http://www. dovepress.com/testimonials.php to read real quotes from published authors. 